\title{
Creativity in Agile Systems Development: A Literature Review
}

\author{
Kieran Conboy ${ }^{1}$, Xiaofeng Wang ${ }^{2}$, and Brian Fitzgerald ${ }^{2}$ \\ ${ }^{1}$ National University of Ireland, \\ Galway, Ireland \\ ${ }^{2}$ Lero Software Engineering Research Centre, \\ University of Limerick, Castletroy, Limerick, Ireland
}

\begin{abstract}
Proponents of agile methods claim that enabling, fostering and driving creativity is the key motivation that differentiates agile methods from their more traditional, beauraucratic counterparts. However, there is very little rigorous research to support this claim. Like most of their predecessors, the development and promotion of these methods has been almost entirely driven by practitioners and consultants, with little objective validation from the research community. This lack of validation is particularly relevant for SMEs, given that many of their project teams typify the environment to which agile methods are most suited i.e. small, co-located teams with diverse, blended skills in unstructured, sometimes even chaotic surroundings. This paper uses creativity theory as a lens to review the current agile method literature to understand exactly how much we know about the extent to which creativity actually occurs in these agile environments. The study reveals many gaps and conflict of opinion in the body of knowledge in its current state and identifies many avenues for further research.
\end{abstract}

\section{Introduction}

The last decade or so has seen the emergence of a number of software development methods as a response to the inefficiency of existing software development methods in rapidly changing environments (Highsmith, 2004). Some of the most popular include eXtreme Programming (XP) (Beck, 2000) and Scrum (Schwaber and Beedle, 2002). This family of methods are now commonly known as 'agile', primarily through the formation of the Agile Alliance and the publication of the Agile Manifesto (Agile Manifesto 2001). Agile methods have been well received by those in the system development community and there is strong anecdotal evidence to suggest that awareness and indeed use of these methods is highly prevalent across the community. Agile methods, given their flexible and light-weight processes, place emphasis on close communication and collaboration in project teams (Beck, 2000; Schwaber and Beedle, 2002). These approaches are typical of the development environments of small to medium software organizations.

Creativity has been advocated as a core part of Information Systems Development (ISD) for many years (Brooks 1987; Elam and Mead 1987; Cougar 1990; Sampler 
and Galleta 1991; Lobert and Dologite 1994; Gallivan 2003; Carayannis and Coleman 2005). Cougar (1990) believed that creative activities should play a pivotal role "in all aspects of IT development, from requirements definition through program design". Lobert and Dologite (1994) propose three reasons for this. Firstly, "technology is evolving on a daily basis and we can continually look for new ways to utilise resources". Secondly, "most simple systems have already been developed and the challenging ones are still ahead". Finally, "many information systems are old, not meeting existing demand, and will soon become obsolete". Researchers such as Gallivan (2003) highlight the importance of creative developers, and Brooks (1987) even contends that the critical problems in ISD may not be addressed by ISD methods per se, but rather how those methods facilitate creativity and improvisation.

The importance of creativity has also been highlighted and the support to creativity claimed within the agile method movement (Highsmith and Cockburn, 2001; Highsmith, 2004; Cockburn and Highsmith, 2001; Highsmith, 2002; Highsmith, 2002a). Agile advocates believe that "creativity, not voluminous written rules, is the only way to manage complex software development problems" (Highsmith and Cockburn, 2001). Cockburn and Highsmith (2001) claim that "Agile methodologies deal with unpredictability by relying on people and their creativity rather than on processes". Highsmith (2002a) contends that "agile approaches are best employed to explore new ground and to power teams for which innovation and creativity are paramount". The literature also illustrates the fact that the requirement for creativity has been highlighted in discussions of specific agile methods, such as eXtreme Programming (XP), one of the most popular agile methods (Highsmith, 2002a; Crispin and House, 2003; Benediktsson et al, 2004). Highsmith (2002a) observers that "although XP contains certain disciplined practices, its intent is to foster creativity and communication". Benediktsson et al (2004) claim that "given the benefits of XP in terms of creativity, value delivery and higher satisfaction levels, it is not surprising that many managers and developers have adopted such practices".

Despite these claims, however, there is a lack of understanding of what constitute creativity in software development in general and to which extent agile methods actually facilitate creativity. The aim of this paper is thus to get a better understanding of the extent to which agile methods facilitate creativity. For our theoretical base we propose a conceptual framework drawn from existing creativity literature, and then use this as a lens to analyse the relevant agile method literature. The paper concludes with a set of recommendations for possible future research.

\section{Creativity Constructs}

Creativity, typically referring to the act of producing new ideas, approaches or actions, is crucial to the success of organizations (Nonaka, 1991; Amabile, 1998). It is seen as a starting point and a necessary but not sufficient condition for organizational innovation, which often refers to the entire process by which an organization generates creative new ideas and converts them into novel, useful and viable commercial products, services, and business practices (Amabile et al., 1996).

A careful literature review reveals a set of creativity constructs-elements that constitute or facilitate creativity of an organization. 


\section{Generation of New Ideas}

One of the simplest work practices facilitating creativity is setting aside time for idea generation (Woodman, Sawyer et al. 1993; Ekvall 1996). However, organisations often tend to over-simplify the creative process, and often misconstrue the setting aside of some "idea time" (Ekvall 1996) as being the only thing needed to be a creative organisation. A number of researchers highlight the distinct lack of resources explicitly dedicated by most organisations to the creative process (Payne 1990). Amabile (1996) details this proposition further, stating that creativity tasks are often bereft of "funds, facilities, materials and information". The critical enablers of creativity which are often ignored include time and resources for testing and experimentation to validate ideas once they have been generated (Anderson and West 1996; Ekvall 1996). Prototyping is often cited as the most important, but most underfunded activity across organisations (Leonard-Barton 1995).

Stakeholder involvement is considered imperative to the creative process, yet many with vested interest are never involved (Nonaka and Takeuchi 1995; Amabile 1996; Ekvall 1996; Mathisen and Einarsen 2004). Flores (1993) exemplifies this by discussing the merits of involving the customer in the innovation process. In a truly creative environment, an organisation's internal and external communication boundaries should be as porous as possible (Leonard-Barton 1995).

Creativity supports also include mechanisms to store knowledge, both tacit and explicit, and distribute that knowledge in order to facilitate creativity (Nonaka and Takeuchi 1995). It is also highly beneficial to measure the creative output produced at the end of a process, both to motivate the team, and to refine the creative process in the next development cycle (Eccles 1991; Grupp 1998; Canibano, Garcia-Ayuso et al. 2000).

\section{Freedom to Act}

The most commonly cited factor of creativity is personnel autonomy, defined by Amabile (1996) as "the ability to decide what work to do and how to do it", where group members are free to define most of their work, and have the freedom to deviate and tailor work practices (Nonaka 1991; Amabile 1996; Ekvall 1996; Mathisen and Einarsen 2004). For many years, empirical research has been showing that creativity is fostered in autonomous work environments (Pelz and Andrews 1966; Paolillo and Brown 1978; Bailyn 1985). According to Siegel and Kaemmerer (1978), ownership of work is an extension of autonomy and a critical driver of creativity. This refers to situations where "group members....originate and develop the ideas, processes and solutions with which they work, as opposed to simply using previously determined solutions" (Mathisen and Einarsen 2004). Anderson and West (1996) found that work practices must do more than just facilitate ownership, but must also encourage participative safety. They found that group members are often adverse to the development of new ideas and processes. In order for ownership of work to actually enhance creativity, the group members must inhabit a "non-threatening environment" 
(Mathisen and Einarsen 2004), built on "trust and openness" (Ekvall 1996) where they know it is safe to present new ideas and ways of doing things.

\section{Vision}

Although autonomy is a key enabler of creativity, the role of the leader is not removed but simply altered. Anderson and West (1996) stress that reckless creativity is often detrimental to an organisation, and that in order for "structured creativity" to flourish, objectives and visions must be "clearly defined, shared, valued and attainable" and all members of the team must have a clear understanding of business goals. In other words, when a new idea is born, there must be a clear value addition to the organisation underpinning that idea (Siegel and Kaemmerer 1978; Amabile 1996; Anderson and West 1996; Amabile 1998). Nonaka and Takeuchi (1995) refers to this concept as "strategic intent", while Siegel and Kaemmerer (1978) referred to this as "consistency" across creative processes "so that members do not choose lines of action which might conflict with the objective of the activity". Along the same vein of thought, Amabile (1996) deem "supervisory encouragement" to be a dimension of creativity, where the role of the manager or the process is to provide "goal clarity". This need to ensure that all creative initiatives follow an aligned path requires creative reality checks to be put in place (Nakamura and Csikszentmihalyi 2001).

\section{Creative Abrasion}

Creative abrasion is a term coined by Hirschberg, the director of Nissan Design International. It is "the recognition of the potential inherent in a portfolio of often conflicting signature skills". It encourages the interaction of individuals who are different in their ideas, biases, personalities, values and skills, as opposed to keeping them apart (Siegel and Kaemmerer 1978; Nonaka 1991; Leonard-Barton 1995). This mode of thinking can be linked back to Plato:

"Only if the various principles - names, definitions, intimations and perceptions - are laboriously tested and rubbed against one another in a reconciliatory tone, without ill will during the discussion, only then will insight and reason radiate forth in each case, and achieve for man the highest possible force".

Outcomes of abrasion include "healthy encounters, exchanges, debates, and viewpoints supported by differing experiences and knowledge" (Leonard-Barton 1995). In operational terms this may be facilitated through co-locating the team and allowing them to observe or swap roles and responsibilities. Leonard-Barton (1995) advocates observation and swapping of roles and responsibilities to encourage creative abrasion. It is important, however, to draw a distinction between creative abrasion and what Ekvall (1996) calls "conflict". In climates where conflict is rife, groups and individuals dislike each other and there is considerable gossip and slander (Mathisen and Einarsen 2004). With regard to creative abrasion however, LeonardBarton (1995) states that although sparks fly, "the sparks are creative not personal". 
Creative abrasion can also be facilitated by diversity, which has been viewed as a central requirement of the creative enterprise for many years, with Andrews (1979) stating that it accounts for $10 \%$ of the variance in creativity across R\&D teams. Siegel and Kaemmerer (1978) suggest a "norms for diversity" stance to be adopted across the organisation, pertaining toward a "positive attitude toward diversity where few behaviours are judged as being deviant". Similarly, Nonaka (1991) calls for "requisite variety", where the group aiming to be creative needs to possess elements of diversity. Leonard-Barton (1995) identifies three types of "signature skill" on which the diversity of a team can be assessed:

- Diverse Task Preferences: People tend to gravitate toward specialisations in certain activities and tasks. As Leonard-Barton (1995) states "specialisation leads to expertise" and the "availability of deep knowledge to apply to problems". However, Leonard-Barton (1995) cites Dougherty's (1992) notion that increasing specialisation also results in "distinct thought worlds" that rarely intersect.

- Diverse Tool and Method Preferences: Leonard-Barton (1995) acknowledges that, as well as having distinct task preferences, people are also diverse in the methods they use to accomplish those tasks.

- Diverse Cognitive Style: Diversity across group members can extend beyond their range of skills and experience. Leonard-Barton (1995) stresses the importance of acknowledging differences in cognitive style, and ensuring that varying styles are used to best effect within the organisation. She cites examples of "personalysis" tests carried out within Nissan Design, where the cognitive preferences of employees were assessed, allowing management to identify those who veered toward rational reasoning as opposed to intuition, or decisive action as opposed to needing larger volumes of information.

\section{Continuous Creativity}

Creativity is often carried out in one-off or very sporadic initiatives. Research following the history of industries over generations has shown that there is always sharp discontinuities with sporadic innovations from time to time (Leonard-Barton 1995). Siegel and Kaemmerer (1978) propose a number of reasons why the creative process must be continuous rather than periodic. For example, creativity revolving around organisational goals must acknowledge that those goals are in a constant state of flux. Therefore outputs of a creative brainstorming session may be obsolete soon after the event. As well as being continuous, creativity thrives on challenging work and work environments (Leonard-Barton 1995; Ekvall 1996). At an operational level, individuals should be emotionally attached to their tasks (Ekvall 1996), regard their tasks as being important and worthwhile (Amabile 1996), and should be intellectually challenged by that work (Amabile 1996). In order to ensure these are achieved, some creativity constructs proposed revolve around the incorporation of "dynamism", "liveliness", "playfulness" and "humorous" (Ekvall 1996) elements of work.

Table 1 is a summary of the creativity constructs suggested in the literature. 
Table 1. Creativity Constructs

\begin{tabular}{|c|c|c|}
\hline Construct & Sub-construct & Creativity Literature \\
\hline \multirow[t]{4}{*}{$\begin{array}{l}\text { Generation } \\
\text { of New } \\
\text { Ideas }\end{array}$} & $\begin{array}{l}\text { Idea Generation, } \\
\text { Tests \& Experiments }\end{array}$ & $\begin{array}{l}\text { (Woodman, Sawyer et al. } \\
\text { 1993; Anderson and West } \\
\text { 1996; Ekvall 1996) }\end{array}$ \\
\hline & $\begin{array}{l}\text { Stakeholder } \\
\text { Involvement }\end{array}$ & $\begin{array}{l}\text { (Nonaka 1991; Flores 1993; } \\
\text { Leonard-Barton 1995; Nonaka } \\
\text { and Takeuchi 1995; Amabile } \\
\text { 1996; Ekvall 1996; Mathisen } \\
\text { and Einarsen 2004) }\end{array}$ \\
\hline & $\begin{array}{l}\text { Information } \\
\text { Storage \& } \\
\text { Distribution }\end{array}$ & $\begin{array}{l}\text { (Nonaka 1991; Nonaka and } \\
\text { Takeuchi 1995) }\end{array}$ \\
\hline & $\begin{array}{l}\text { Measurement of } \\
\text { Output }\end{array}$ & $\begin{array}{l}\text { Eccles 1991; Grupp 1998; } \\
\text { Canibano, Garcia-Ayuso et al. } \\
\text { 2000) }\end{array}$ \\
\hline $\begin{array}{l}\text { Freedom } \\
\text { to Act }\end{array}$ & $\begin{array}{l}\text { Autonomy, Ownership } \\
\& \\
\text { Safety }\end{array}$ & $\begin{array}{l}\text { (Pelz and Andrews 1966; } \\
\text { Paolillo and Brown 1978; } \\
\text { Siegel and Kaemmerer 1978; } \\
\text { Bailyn 1985; Nonaka 1991; } \\
\text { Amabile 1996; Ekvall 1996; } \\
\text { Mathisen and Einarsen 2004) }\end{array}$ \\
\hline \multirow[t]{2}{*}{ Vision } & $\begin{array}{l}\text { Understanding of } \\
\text { Business Goals }\end{array}$ & $\begin{array}{l}\text { (Siegel and Kaemmerer 1978; } \\
\text { Shiba, Graham et al. 1992; } \\
\text { Amabile 1996; Anderson and } \\
\text { West 1996; Amabile 1998) }\end{array}$ \\
\hline & $\begin{array}{l}\text { Creative Reality } \\
\text { Checks }\end{array}$ & $\begin{array}{l}\text { (Nakamura and } \\
\text { Csikszentmihalyi 2001) }\end{array}$ \\
\hline \multirow[t]{2}{*}{$\begin{array}{l}\text { Creative } \\
\text { Abrasion }\end{array}$} & $\begin{array}{l}\text { Observation/ Swapping } \\
\text { of } \\
\text { Roles/ Responsibilities }\end{array}$ & $\begin{array}{l}\text { (Siegel and Kaemmerer 1978; } \\
\text { Nonaka 1991; Leonard-Barton } \\
\text { 1995) }\end{array}$ \\
\hline & $\begin{array}{l}\text { Task, Method, \& } \\
\text { Cognitive } \\
\text { Diversity }\end{array}$ & $\begin{array}{l}\text { (Siegel and Kaemmerer 1978; } \\
\text { Andrews 1979; Nonaka 1991; } \\
\text { Leonard-Barton 1995) }\end{array}$ \\
\hline \multirow[t]{2}{*}{$\begin{array}{l}\text { Continuous } \\
\text { Creativity }\end{array}$} & $\begin{array}{l}\text { Continuous } \\
\text { Development }\end{array}$ & $\begin{array}{l}\text { (Allen 1977; Siegel and } \\
\text { Kaemmerer 1978; Leonard-Barton } \\
\text { 1995) }\end{array}$ \\
\hline & Challenging Work & $\begin{array}{l}\text { (Leonard-Barton 1995; } \\
\text { Amabile 1996; Ekvall 1996) }\end{array}$ \\
\hline
\end{tabular}

\section{A Critical Consideration of Creativity Constructs in Agile Methods}

This section examines the agile methods literature in general, and XP literature in particular, for evidence of the various constructs of creativity listed in the framework. 


\section{Generation of New Ideas}

There are various principles and practices across the agile method spectrum that could be classified as idea generation, tests or experiments. Requirements development is referred to as "exploration" in XP (Stephens and Rosenberg 2003), as "exploratory $360^{\circ}$ " in Crystal (Cockburn 2001), and "speculation" in ASD (Highsmith 1999). Highsmith (2004) calls for the setting of "Big Hairy Audacious Goals (BHAGS)" in ASD, and for developers to follow in the footsteps of "great explorers such as Cook, Magellan, Shackleton and Columbus". He is also one of the only authors to show how current agile practices such as self-organising teams, encouraging interaction and participatory decision-making all have the potential to facilitate creativity and exploration.

However, there is little evidence throughout the literature that suggests these phases go beyond the traditional elicitation of standard requirements to activities which result in new ground-breaking and innovative requirements and functionality. In fact, the exploration phase of XP is the only instance where the execution of tests and experiments are explicitly stated (Jeffries, Anderson et al. 2000; Auer and Miller 2002). As Jeffries et al (2000) describe, during the exploration phase, "the programmers will be experimenting with ways of building the system", and "trying experiments that inform them how costly the various stories and features will be".

Regarding stakeholder involvement, the on-site customer has made the single most significant contribution (Beck 1999; Beck 1999; Jeffries, Anderson et al. 2000; Beck and Fowler 2001; Auer and Miller 2002). The purveyors of agile methods have indeed recognised that "a good customer collaborating with a good development team can significantly increase the success of a project" (Schuh 2005). This has grown from a single on-site customer, which has been dismissed by Beck himself as "an error of early XP thinking", and many agile method texts now recommend customer teams be "equal to or larger in size than the programming team" (McBreen 2003). However, there are two shortcomings of the agile methods research in this area:

- Firstly, to date, all of the discussion on agile methods has focused on the onsite customer where the customer travels to the development site or area. The concept of an on-site developer who travels to the customer's area of work to get a true feeling of what the customer wants and does on a day-to-day basis has received no attention.

- Secondly, Augustine (2005) is one of the few researchers in the agile method arena who explicitly extends the notion of the stakeholder beyond the customer. He recommends the development of a stakeholder map (see Figure 1). None of the proprietary agile method texts focus on this broader notion of stakeholder as far as this study is aware.

The extent to which agile methods facilitate information storage and distribution is certainly a matter for debate. On one hand, circulation of information is increased due to co-located teams, pair programming, daily meetings and other practices (Beck 1999; Beck 1999; Jeffries, Anderson et al. 2000; Beck and Fowler 2001; Auer and Miller 2002; Cockburn 2002; Schwaber and Beedle 2002). Indeed one of the core values of the Manifesto is to value "individuals and interactions over processes and 
tools". On the other hand however, reduced documentation and increased reliance on "oral documentation" (McBreen 2003) has significant negative consequences on the quantity and quality of information stored and distributed to various team members and groups (see McBreen (2003) and Stephens and Rosenberg (2003) for a more extensive discussion of these problems). Regardless of the debate as to whether agile methods improve the circulation of information, no literature focuses on the relationship between creativity and information storage or distribution in an agile method context.

There is also a distinct lack of discussion regarding the measurement of creativity in the agile method literature to date. This includes both assessment of creative behaviours and processes, as well as any attempts to assess how innovative the final system is.

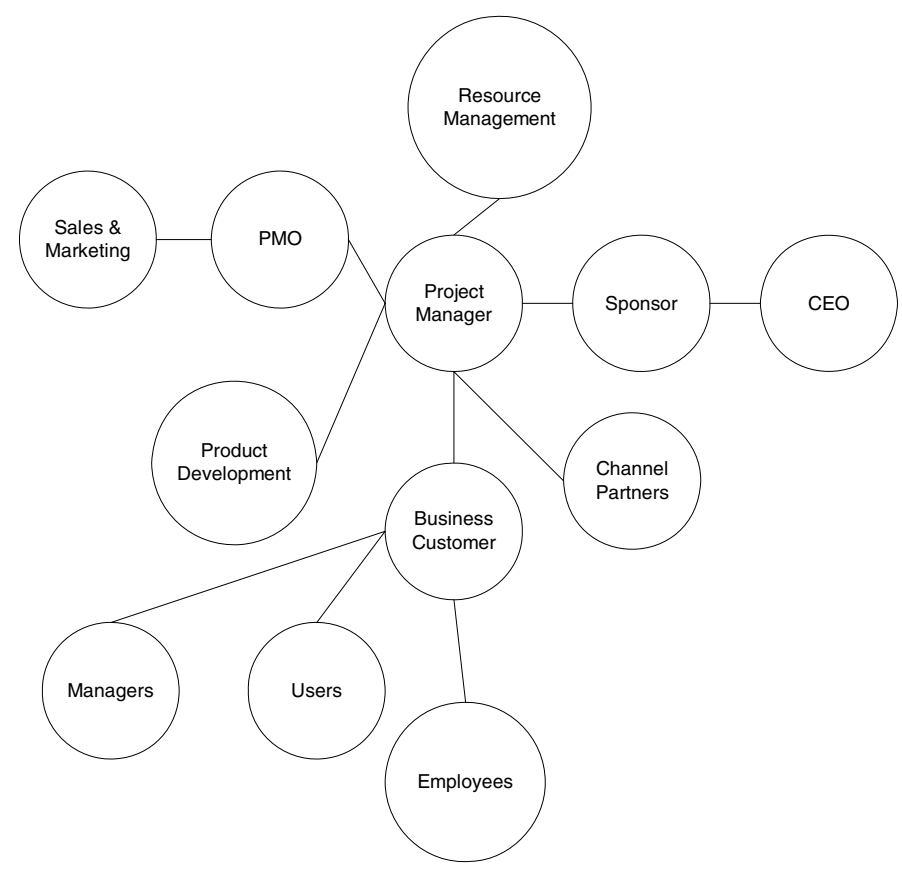

Fig. 1. Stakeholder Map (Augustine, 2005)

\section{Freedom to Act}

Unlike many of the exemplars listed in Table 1, autonomy and ownership are constructs of creativity often cited in agile method research. The Agile Manifesto devotes a section to conveying the belief that "the best architectures, requirements, and designs emerge from self-organising teams" (Fowler and Highsmith 2001). Koch (2005) senses that the agile community has done a lot more than just introduce selforganisation, and that "the agile methods embrace the recent movement toward selfmanaged, self-directed and self-organising teams". Referring to Amabile's (1996) 
definition of autonomy where the team possesses "the ability to decide what work and how to do it", it is clear that the agile method purveyors have adopted an interpretation that is not too dissimilar. Agile methods require a shift from commandand-control management to "leadership-and-collaboration" (Nerur, Mahapatra et al. 2005), or what Highsmith (2004) refers to as an "egalitarian workplace". According to the agile belief structure, the team are counted "as an entity that has its own knowledge, perspective, motivation and expertise", "are treated as a partner with management and the customer", and are "capable of providing insight, affecting decisions, and negotiating commitments" (Koch 2005). Method-specific examples include Scrum which holds self-organising teams as one of its principles (Schwaber and Beedle 2002).

The notion of participative safety was proposed as a key exemplar of creativity, where a non-threatening environment was deemed to be a critical facilitator of creativity. Past literature has focused on trust in ISD (e.g. Hohnmann 1997), and in an agile context, Poppendieck and Poppendieck (2003) refer to safety in the context of LSD, and Cockburn's Crystal Clear (Cockburn 2001) also lists personal safety as a property of the method.

\section{Vision}

The understanding of business goals and objectives seems to be well catered for by today's agile methods. As Jeffries et al (2000) state, "your chief weapon is business value". "Agile methods are popular in the business community because they force concentration on business value above purely technical pursuits" (Augustine 2005). Agile methods achieve this through various mechanisms such as constant prioritisation of work in order of business value (Augustine 2005). Prioritisation is done by customers through user stories and not technical personnel (Beck 1999; Augustine 2005), as is the case with Scrum sprints for example (Schwaber and Beedle 2002). A further example is ASD's project vision that "defines the commissioned system by its business objectives" (Schuh 2005). Also, the on-site customer provides frequent "checks and balances" to ensure business value is being achieved (McBreen 2003).

With regard to reality checks, it should be noted that McBreen's point above cites the customer as a provider of checks and balances to ensure new ideas have some business value. Conversely, Highsmith (2004) indicates that there is a similar role required within the team of developers. He outlines two groups of developers; the "creators", who "always want to go for the big prize", and are constantly seeking "innovation, new product development, new processes and practices", while on the other hand, "we also require stewards who can't get excited about an innovation until .... they understand how the economic value will be created".

\section{Creative Abrasion}

Observation and swapping of roles and responsibilities is commonplace on agile ISD projects, although again this is not explicitly stated as a goal. Rather it is achieved implicitly through other agile practices, where multitasking and self-organisation are 
encouraged (Augustine 2005), roles and responsibilities are stated at a much higher level of granularity (Beck and Fowler 2001), short iterations mean that a developer need not be tied to a specific role for a long period of time (Beck 1999; Cockburn 2001; Schwaber and Beedle 2002), and pair programming and co-located teams allow easy observation between developers (Williams, Kessler et al. 2000; Canfora, Cimitile et al. 2005). Few researchers have examined the impact of creative abrasion and conflict in the ISD process (see Domino, Collins et al. 2003 for a comprehensive literature review), despite the fact that Cohen et al (2003) found such conflict to be a frequent and significant occurrence on ISD projects. Newman and Robey (1992) state that the generation and resolution of conflict is of central theoretical interest to ISD researchers, yet there is "little empirical work relating to conflict handling styles and ISD" (Domino, Collins et al. 2003). There is no agile method research which focuses on the potential for conflict to contribute to creativity, which is strange given agile method practices such as co-located teams and pair programming increase personal interaction and the potential for such conflict to occur (Domino, Collins et al. 2003).

Diversity of any form is rarely discussed throughout the agile method literature, and Coplien and Harrison (2005), in their discussion of organisational patterns in agile development, are the only authors to explicitly demand group diversity as a tenet of an agile approach. The mainstream methods such as XP and Scrum make no reference to any form of group diversity.

\section{Continuous Creativity}

Continuous development is encouraged throughout the agile method literature via continuous evaluation (Schuh 2005), continuous testing (Beck 1999; Crispin and House 2003), continuous integration (Beck 1999; Jeffries, Anderson et al. 2000; Highsmith 2002; Augustine 2005), and frequent and continuous code releases (Beck 1999; Jeffries, Anderson et al. 2000; Cockburn 2001; Augustine 2005). In Scrum, the product and sprint backlogs ensure that there is always more functionality to be developed even if all of the initial requirements set out for a sprint are completed ahead of time (Schwaber and Beedle 2002). Also, the fact that agile methods such as Scrum, XP and Crystal Clear all recommend daily meetings also encourages continuous work (Cockburn 2001; Schwaber and Beedle 2002). The 40-hour week is a rule of XP that is said to contribute to continuous development, but as McBreen (2003) notes, this has been renamed "sustainable pace", which gives further credence to the fact that XP emphasises "long term, continuous performance".

In terms of challenging work, Beck (1999) claims that the developer should be "fresh and eager every morning, and tired and satisfied every night". McBreen (2003) describes XP as "a high-intensity approach to software development". His rationale for this is that (i) the planning practices "are geared toward delivering maximal value in minimum calendar time", and (ii) "delivering incrementally in short time-boxed iterations to exacting test standards is rewarding but difficult". Many of the agile method practices such as on-site customer, daily meetings, and pair programming can all be argued to contribute to a more challenging environment for the ISD team. However, again these are suppositions that have not been covered in any depth by existing research. 


\section{Conclusions and Further Research}

To summarise, the general ISD literature validates creativity as being relevant to the field, and has frequently called for recognition of the critical role creativity plays in the successful development of a system. In relation to agile methods research, the literature points to a number of quotes and references that not only validate the relevance of creativity to agile methods, but highlight it as a key driving force behind their emergence. However, the extent to which agile methods handle the various exemplars of creativity is very inconclusive. The literature identified some exemplars which are handled by agile methods, some which are not, and in some cases it could be argued that agile methods may even act as inhibitors to some exemplars.

Some of the most prominent issues identified in this study which may warrant further research include:

- $\quad$ regarding generation of new ideas, study of routinising exploratory activities and allocating organizational resources to them in software development projects; understanding the involvement of stakeholders other than customers in software development; investigating the relationship between creativity and information storage or distribution in an agile method context where there is an un-emphasis of formal methods to storing and distributing information; and assessing creative behaviours and processes of agile method projects, including the measurement of how creative the final software system is.

- $\quad$ in terms of creative abrasion, examining the impact of creative abrasion and conflict in agile processes to understand the impact of agile practices on project teams and their contribution to creativity; and study of how agile methods influence team diversity.

- with respect to continuous creativity construct, establishing empirical evidence of the contribution of agile practices to create a challenging but rewarding working environment for agile method teams.

\section{References}

Allen, T.: Managing the flow of technology: Technology transfer and the dissemination of technological information within the R\&D organization. MIT Press, Cambridge (1977)

Amabile, T.: Creativity in Context. Westview Press, Boulder (1996)

Amabile, T.: How to Kill Creativity. Harvard Business Review 76(5), $77-87$ (1998)

Anderson, N., West, M.: The team Climate Inventory Development Exercises. Windsor, England (1996)

Andrews, F.: Scientific Productivity. Cambridge University Press, Cambridge (1979)

Auer, K., Miller, R.: Extreme Programming Applied - Playing to Win. Addison-Wesley, Reading (2002)

Augustine, S.: Managing Agile Projects. Prentice-Hall, Upper Saddle River (2005)

Bailyn, L.: Autonomy in the Industrial R\&D Laboratory. Human Resource Management 24(1), 129-146 (1985)

Beck, K.: Embracing change with extreme programming. IEEE Computer 32(10), 70-77 (1999)

Beck, K.: Extreme Programming Explained. Addison Wesley, Reading (1999) 
Beck, K., Fowler, M.: Planning eXtreme Programming. Addison-Wesley, Boston (2001)

Brooks, F.: No Silver Bullet: Essence and Accidents of Software Engineering. IEEE Computer 20(4), 10-19 (1987)

Canfora, G., Cimitile, A., et al.: Empirical study on the productivity of the pair programming. In: Baumeister, H., Marchesi, M., Holcombe, M. (eds.) XP 2005. LNCS, vol. 3556, pp. 92 99. Springer, Heidelberg (2005)

Canibano, L., Garcia-Ayuso, M., et al.: Shortcomings in the Measurement of Innovation: Implications for Accounting Standard Setting. Journal of Management and Governance 4(4), 319-342 (2000)

Carayannis, E., Coleman, J.: Creative system design methodologies. Technovation 25(3), 831840 (2005)

Cockburn, A.: Crystal Clear: A human-powered software development methodology for small teams. Addison-Wesley, Reading (2001)

Cockburn, A.: Agile Software Development. Addison-Wesley, Reading (2002)

Cohen, C., Birkin, S., et al.: Managing Conflict in Software Testing: Lessons from the Field. Communications of the ACM 47(1), 76-81 (2003)

Coplien, J., Harrison, R.: Organisational Patterns of Agile Software Development. Pearson, Upper Saddle River (2005)

Cougar, J.: Ensuring creative approaches in information system design. Managerial and Decision Economics 11(2), 281-295 (1990)

Crispin, L., House, T.: Testing Extreme Programming. Pearson, Boston (2003)

Domino, M., Collins, R., et al.: Conflict in Collaborative Software Development. In: SIGMIS Conference 2003, Philadelphia, PA, pp. 44-51 (2003)

Dougherty, D.: The Illegitimacy of Successful Product Innovation in Established Firms. Organisation Science 5(2), 200-218 (1992)

Eccles, R.: The Performance Measurement Manifesto. Harvard Business Review 69(1), 131137 (1991)

Ekvall, G.: Organisational Climate for Creativity and Innovation. European Journal of Work and Organisational Psychology 5(1), 105-123 (1996)

Elam, J., Mead, M.: Designing for creativity: considerations for DSS development. Information \& Management 13(2), 215-222 (1987)

Flores, F.: Innovation by Listening Carefully to Customers. Long Range Planning 26(3), 95102 (1993)

Fowler, M., Highsmith, J.: The Agile Manifesto. Software Development 9(8), 28-32 (2001)

Gallivan, M.: The Influence of Software Developer's Creative Style on Their Attitudes To and Assimilation of a Software Process Innovation. Information \& Management 40(1), 443-465 (2003)

Grupp, H.: Foundations of the Economics of Innovation Theory, Measurement and Practice. Elgar Publishing, Cheltenham (1998)

Highsmith, J.: Adaptive Software Development. Dorset House, NY (1999)

Highsmith, J.: Agile Software Development Ecosystems. Pearson, Boston (2002)

Highsmith, J.: Agile Project Management. Addison-Wesley, Boston (2004)

Hohnmann, L.: Journey of the Software Professional. Prentice-Hall, Upper Saddle River (1997)

Jeffries, R., Anderson, A., et al.: Extreme Programming Installed. Addison-Wesley, Reading (2000)

Koch, A.: Agile Software Development: Evaluating the Methods for Your Organisation. Artech House, Norwood (2005)

Leonard-Barton, D.: Wellsprings of Knowledge: Building and Sustaining the Sources of Innovation. Harvard Business School Press, Boston (1995)

Lobert, B., Dologite, D.: Measuring creativity of information system ideas: an exploratory investigation. In: IEEE Proceedings of the Annual Hawaii International Conference on Systems Science, Hawaii. IEEE Computer Society Press, Los Alamitos (1994) 
Mathisen, G., Einarsen, S.: A Review of Instruments Assessing Creative and Innovative Environments Within Organisations. Creativity Research Journal 16(1), 119-140 (2004)

McBreen, P.: Questioning Extreme Programming. Addison-Wesley, Boston (2003)

Nakamura, J., Csikszentmihalyi: Catalytic Creativity: The Case of Linus Pauling. American Psychologist 56(4), 360-362 (2001)

Nerur, S., Mahapatra, R., et al.: Challenges of Migrating to Agile Methodologies. Communication of the ACM 48(5), 72-78 (2005)

Newman, M., Robey, D.: A Social Process Model of User-Analyst Relationships. MIS Quarterly 16(2), 249-266 (1992)

Nonaka, I.: The Knowledge-Creating Company. Harvard Business Review 69(6), 96-104 (1991)

Nonaka, I., Takeuchi, H.: The Knowledge-Creating Company. Oxford University Press, Oxford (1995)

Paolillo, J., Brown, W.: How Organisational Factors Affect R\&D Innovation. Research Management 21(1), 12-15 (1978)

Payne, R.: The effectiveness of research teams: A review. In: West, M., Farr, J. (eds.) Innovation \& Creativity at Work, pp. 101-122. Wiley, Chichester (1990)

Pelz, D., Andrews, F.: Scientists in Organisations. Wiley, NY (1966)

Poppendieck, M., Poppendieck, T.: Lean Software Development: An Agile Toolkit. AddisonWesley, Reading (2003)

Sampler, J., Galleta, D.: Individual and organisational changes necessary for the application of creativity techniques in the development of information systems. In: Proceedings of the 24th Annual Hawaii International Conference on System Sciences, Hawaii. IEEE Society Press, Los Alamitos (1991)

Schuh, P.: Integrating Agile Development in the Real World. Charles River Media, Hingham (2005)

Schwaber, K., Beedle, M.: Agile Software Development with Scrum. Prentice-Hall, Upper Saddle River (2002)

Shiba, S., Graham, A., et al.: A New American TQM: Four Practical Revolutions in Management. The Center for Quality Management and Productivity Press, Boston (1992)

Siegel, S., Kaemmerer, W.: Measuring the Pereived Support for Innovation in Organisations. Journal of Applied Pschology 63(3), 553-562 (1978)

Stephens, M., Rosenberg, D.: Extreme Programming Refactored. Apress (2003) ISBN 159059-096-1

Williams, L., Kessler, R., et al.: Strengthening the Case for Pair-Programming. IEEE Software 17(4), 19-25 (2000)

Woodman, R., Sawyer, J., et al.: Toward a Theory of Organisational Creativity. Academy of Management Review 18(2), 293-321 (1993) 